\title{
Asymmetric Conjugate Addition of Arylthiols to Enoates and Its Application to Organic Synthesis of Biologically Potent Compounds
}

\author{
Katsumi NisHimURA and Kiyoshi TOMIOKA \\ Graduate School of Pharmaceutical Sciences, Kyoto University, \\ Yoshida, Sakyo-ku, Kyoto 606-8501, Japan
}

(Received September 30, 2002)

\begin{abstract}
As a part of our studies aimed at asymmetric catalytic reactions by using an external chiral ligand, we have developed a catalytic asymmetric addition reaction of an arylthiol to $\alpha, \beta$-unsaturated esters under the control of an external chiral ligand. The characteristic of our technology is a double activation of a thiol by lithiation and chelate formation with a chiral tridentate amino diether ligand, which simultaneously and effectively controls a stereochemistry of the reaction. One significant feature of an arylthiol is a bulky 2-substitution on aryl group, which enables the formation of a really reactive monomeric thiolate species. s-Cis conformation and capability of electron lone pair-differentiating coordination of a carbonyl oxygen to lithium are structural requirements of the substrates for high enantioselectivity. The enantioselectivity came up to $97 \%$ under the cited conditions. Asymmetric protonation of a transient enolate, generated by conjugate addition of a lithium thiolate to an enoate, was also realized. The stereochemistry of the protonation was controlled by the conformation of initially formed transient enolate in a 1,2-asymmetric induction manner. This technology enabled the asymmetric synthesis of $(S)$-naproxene. Stereoselective tandem $\mathrm{C}-\mathrm{S}$ and $\mathrm{C}-\mathrm{C}$ bond-forming reaction was developed as a logical extension by trapping the transient enolate intermediate with an aldehyde as a carbo-electrophile in the presence of phenylthiotrimethylsilane as an equilibrium-shift reagent. This tandem reaction was extended to a stereoselective cyclization of $\omega$-oxo- $\alpha, \beta$-unsaturated esters initiated by a lithium thiolate. Stereoselectivity of both tandem inter- and intramolecular reaction is predictable by an allylic strain-controlled conformation model of the enolate, in which an approach of aldehyde takes place anti to $\mathrm{C}-\mathrm{S}$ bond through coordination of an aldehyde oxygen to lithium. Total synthesis of (-)-neplanocin A was achieved by using the tandem cyclization as a key tool for the direct construction of a five-membered carbocycle where every carbon is functionalized.
\end{abstract}

Key words_asymmetric conjugate addition; asymmetric protonation; stereoselective $\mathrm{C}-\mathrm{C}$ bond formation; stereoselective cyclization; thiol; chiral ligand

\section{INTRODUCTION}

Reactivity enhancement of chemical species is a fundamental of organic chemistry. We have been involved in reactivity enhancement of carbonucleophiles such as organolithium, ${ }^{1-8)}$ Grignard reagent, ${ }^{9-11)}$ organozinc, ${ }^{12-14)}$ lithium phosphonate, ${ }^{15-19)}$ and lithium enolate ${ }^{20-22)}$ by forming a chelate with a ligand. ${ }^{23-27)}$ The successful above technology was extended to heteronucleophiles, nitrogen, oxygen, ${ }^{28)}$ and sulfur atoms which were activated by lithiation. We describe herein our approach to chemistry of sulfur nucleophiles.

The conjugate addition reaction of a thiol to an electron-deficient multiple bond is one of the excellent

京都大学大学院薬学研究科（干606-8501 京都市左京区 吉田下阿達町46-29)

E-mail: nishi@pharm.kyoto-u.ac.jp

*本総説は, $\mathrm{KN}$ の平成 13 年度日本薬学会近畿支部学 術奨励賞の受賞業績に加筆したものである. methods for forming a carbon-sulfur bond. ${ }^{29)}$ Since the sulfur functional group can be removed or converted to other functional groups, the chemical synthetic usefulness of it is very high. ${ }^{30,31)}$ The history of catalytic asymmetric addition of thiol is old, and in 1970's, Wynberg et al. developed a method that relied on a cinchona alkaloid as an asymmetric catalyst. ${ }^{32,33)}$ Afterwards, many asymmetric addition reactions including proline-derived chiral amino alcohol-catalyzed highly selective reaction developed by Mukaiyama's group ${ }^{34,35)}$ were reported. ${ }^{36-41)}$ These reactions, however, lack generality, and are applicable only to highly reactive substrates such as enones because of poor nucleophilicity of thiolate that is activated by ammonium. In this study, the crucial factors for high reactivity as well as enantioselectivity were double activation of thiol by lithiation and subsequent chelate formation of lithium with a tridentate chiral ligand. 


\section{STRUCTURAL REQUIREMENTS OF THE CHIRAL LIGAND ${ }^{42}$}

The key to successful asymmetric reaction is the construction of effective asymmetric environment around the lithium thiolate. Chiral diether ligand $\mathbf{4}$ was designed to construct effective asymmetric environment in the vicinity of lithium through chelateformation, where the methyl group on oxygen atom of $\mathbf{4}$ is fixed in the specific position of the five-membered chelate because of a steric repulsion with adjacent phenyl group. ${ }^{1)}$ It is important to note that the ether oxygen atoms behave like an atom with chirality by the conformational bias. ${ }^{43}$ ) This design has been a basis of our various catalytic asymmetric reactions. However, the reaction of thiophenol 2a with methyl crotonate 1 in the presence of $8 \mathrm{~mol} \%$ of 4 and lithium thiophenolate gave an adduct $\mathbf{3 a}$ in a marginal enantioselectivity (Fig. 1). Then we screened our chiral ligands 5-7 for the evaluation of their ability in enantioselectivity. Finally, we have found that chiral tridentate amino diether ligand $\mathbf{7}$ gave $\mathbf{3 a}$ in $71 \%$ ee.

For the structure of a chiral ligand with high asymmetric induction ability, trans diphenyl groups on an ethylene skeleton, amino group of strong coordination ability, and three heteroatoms which satisfy tetravalency of lithium by coordination were necessary. These results indicate that bicyclo [3.3.0] complex $\mathbf{8}$, which is formed by chelation of $\mathbf{7}$ with lithium thiolate, is a catalytic nucleophilic species (Fig. 1).

\section{STERIC TUNING OF REACTIVITY AND ENANTIOSELECTIVITY ${ }^{44}$}

The enantioselectivity of the addition of thiophenol to methyl crotonate was at most $71 \%$. To improve the enantioselectivity as well as reactivity, we examined steric effect of substituents on a phenyl ring of thiophenol. Surprisingly and fortunately for us, a bulky $t$-butyl group at 2-position of thiophenol drastically improved the enantioselectivity up to $90 \%$ ee (Table 1). It is an established chemical knowledge that the reactivity decreases when a bulky group is introduced to the vicinity of the reaction site, because steric hindrance around the site increases. In this specific case, 2-position of thiophenol is substituted with a bulky alkyl group. However, truth is stranger than knowledge, the reaction time shortened in order of the bulkiness of the substituents, and the enantioselectivity was also improved in proportion to it.
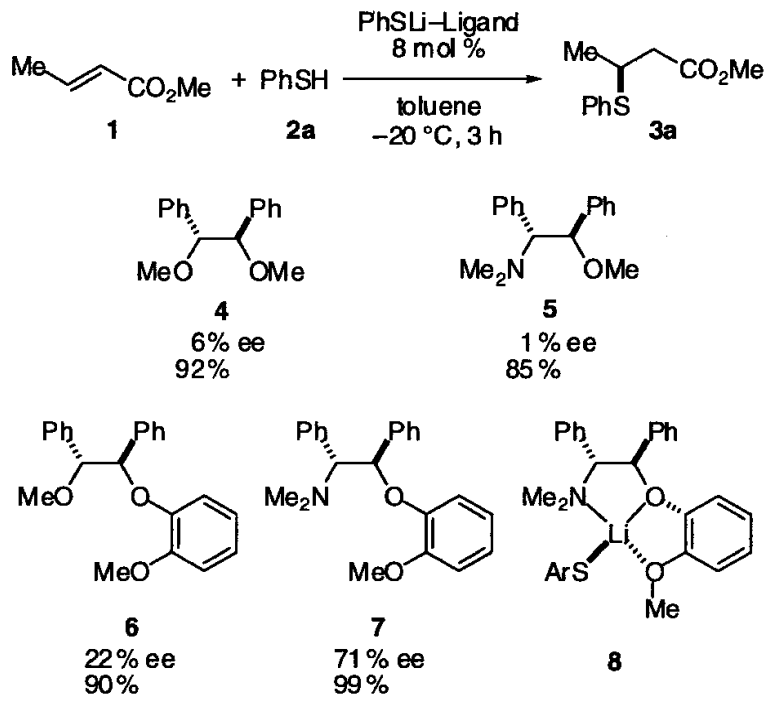

Fig. 1. Ligand Effect on Selectivity

Table 1. Steric Tuning of Reactivity and Enantioselectivity

\begin{tabular}{|c|c|c|c|c|c|c|}
\hline \multirow[b]{2}{*}{ entry } & \multirow{2}{*}{$\begin{array}{l}1 \\
\text { a-e }\end{array}$} & \multicolumn{2}{|c|}{$2 a-e$} & $\frac{\begin{array}{c}\text { toluen } \\
-20^{\circ} \mathrm{C}\end{array}}{8 \mathrm{~mol} \%}$ & \multicolumn{2}{|c|}{$\underbrace{\mathrm{S}}_{3 a \mathrm{e}}$} \\
\hline & & $\mathbf{R}$ & time/h & yield/\% & ee $/ \%$ & $R / S$ \\
\hline 1 & $\mathbf{a}$ & $\mathrm{H}$ & 3 & 99 & 71 & $S$ \\
\hline 2 & b & $\mathrm{Me}$ & 2 & 93 & 79 & $S$ \\
\hline 3 & c & $i-\operatorname{Pr}$ & 2 & 99 & 85 & \\
\hline 4 & d & $t-\mathrm{Bu}$ & 1 & 99 & 90 & \\
\hline 5 & e & TMS & 1 & 99 & 88 & $S$ \\
\hline $6^{a)}$ & e & TMS & 120 & 99 & 97 & $S$ \\
\hline
\end{tabular}

${ }^{\text {a) }}$ The reaction was carried out in toluene-hexane $(1: 1)$ at $-78^{\circ} \mathrm{C}$.

The enantioselectivity came up to $97 \%$ by using 2 trimethylsilylthiophenol $\mathbf{2 e}$ and by cooling down the reaction temperature to $-78^{\circ} \mathrm{C}$ (entry 6) .

According to the kinetic study by S-Garwood, the phenylthiolate anion having a substituent at the 2-position shows remarkably large kinetic constant in comparison with the thiophenolate of nosubstitution. ${ }^{45)}$ The large kinetic constant was attributed to desolvation of the thiolate by steric hindrance of the substituent. And, according to the Xray crystal analysis by Banister et al., lithium arylthiolate having 2-methyl group exists as a monomer in which three pyridine molecules coordinated to lithium, while the lithium thiophenolate of 
no-substitution is the infinite chain structure. ${ }^{46)}$ When these preceding knowledge are applied to our catalytic reactive species, main factors for the selectivity and reactivity improvements are desolvation of the lithium thiolate by steric hindrance of 2-substituent and formation of sterically restricted monomeric reactive species, in which three heteroatoms of tridentate chiral amino diether ligand 7 coordinate to lithium. Thinking that the activation energy of the reaction corresponds to that of desolvation, our methodology for activation of the lithium thiolate is quite rational.

The TMS group on aromatic ring is easily removed off by treating with trifluoromethanesulfonic acid, indicating equivalence of 2-TMS-thiophenol to thiophenol. The adduct $\mathbf{3 e}$ was converted to $\mathbf{3 a}$ without any loss of stereochemical rigidity.

The stereochemical course of the reaction is predictable based on assumption that the reaction proceeds through ternary complex, in which the coordination of methoxy group to lithium is replaced by the carbonyl oxygen of the ester (Fig. 2).47)

Recently, asymmetric conjugate addition reactions of thiol activated by metalation have been developed by Shibasaki' ${ }^{48,49)}$ and Node' ${ }^{50,51)}$ groups, respectively, and the excellent methods using chiral Lewis acid have been reported by Kanemasa' $\mathrm{s}^{52}$ and Hashimoto's ${ }^{53,54)}$ groups, independently.

\section{STRUCTURAL REQUIREMENTS OF THE SUBSTRATE ${ }^{55)}$}

Two kinds of conformers, s-trans and s-cis of enoate, are possible for a double bond conjugated to a carbonyl group. The reaction of $\mathbf{9 c}$ having fixed strans structure with thiol $\mathbf{2 e}$ in the presence of $\mathbf{8}$ gave an adduct of poor enantioselectivity (Table 2). Nevertheless, higher selectivity was not observed in the reaction of 9d having fixed s-cis structure. Higher enatioselectivities $59 \%$ and $94 \%$ were finally obtained
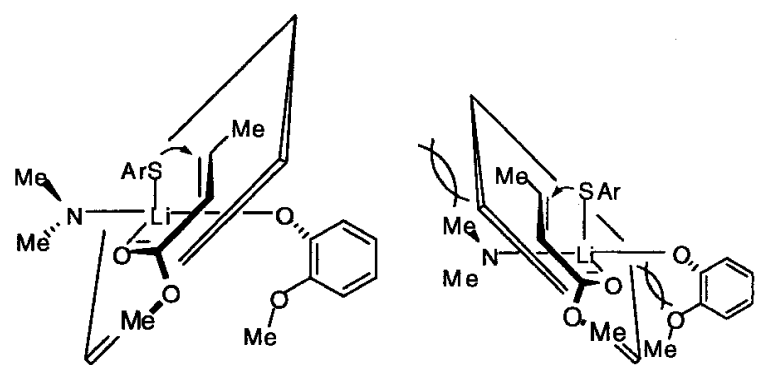

Fig. 2. Enantiofacial Selection
Table 2. Structural Requirements of Substrate

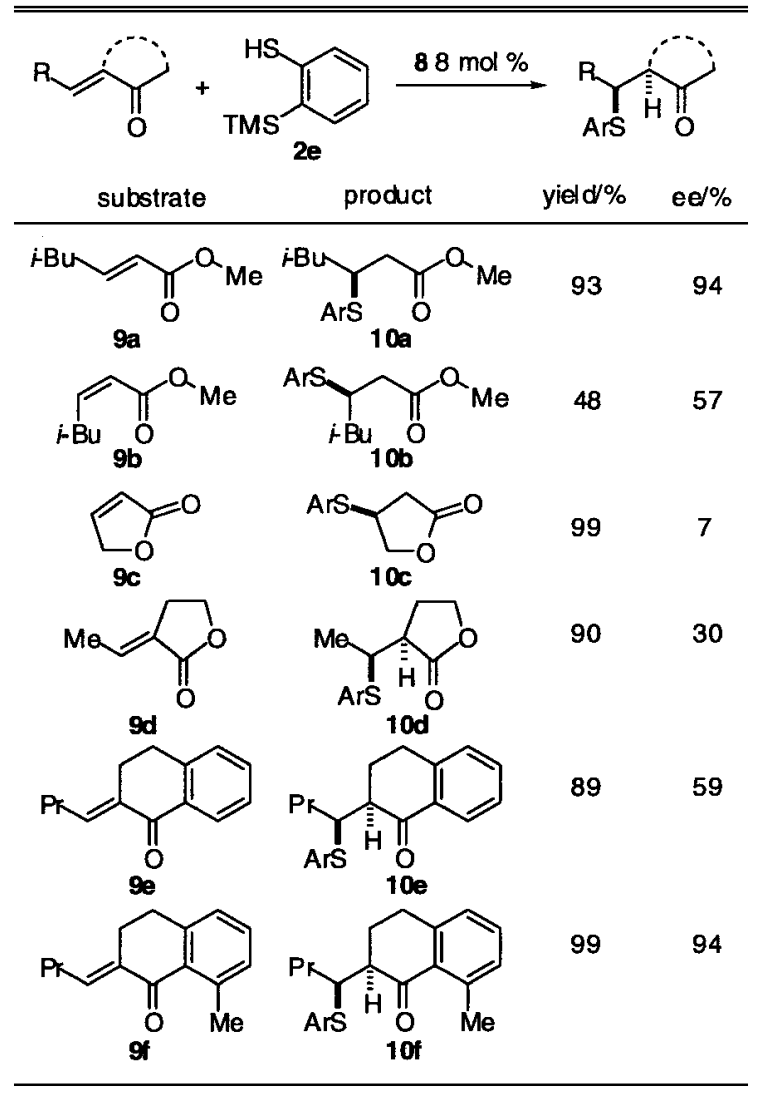

in the reaction of $9 \mathbf{e}$ and $9 \mathrm{f}$ bearing a sterically hindered group at the opposite side of carbonyl group to reacting double bond.

These results indicate that two structural factors are important for high enantioselectivity; one is a capability in taking s-cis conformation, another is a lone pair-differentiating coordination of a carbonyl oxygen atom to lithium. In other words, a lone pair of olefin side is able to coordinate to lithium, and opposite side one is blocked to coordinate. These structural requirements are generally operative in the reaction of $\mathbf{2 e}$, and further supported by the reaction with linear enones (Fig. 3).

The analysis described above indicates that the unsaturated esters and enones react with $\mathbf{8}$ in the s-cis conformation. Chamberlin et al. reported that an enone reacts with hydride reagent in s-cis conformation in the conjugate reduction reaction, in which the conformational stability in ground state of the enone is reflected in the conformation of transition state. ${ }^{56}$ ) In the meantime, our finding is that enone reacts with thiolate in s-cis conformation in spite of the conformational stability in ground state, and this is consis- 


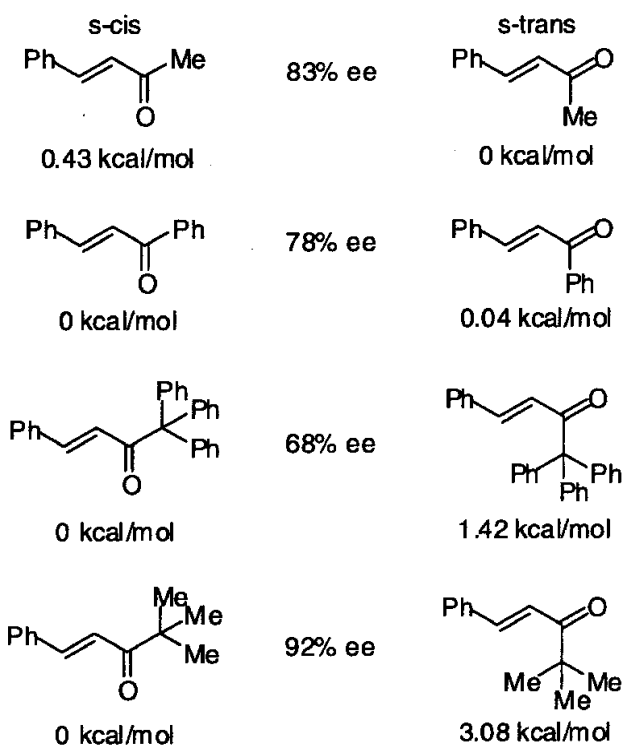

Fig. 3. MM2 Energy Differences of Enones and Asymmetric Conjugate Addition of $2 \mathbf{e}$ to Enones

tent with Curtin-Hammet principle. ${ }^{57)}$

\section{STEREOCHEMISTRY OF PROTONATION PROCESS ${ }^{55}$}

Conjugate addition of a thiol is constituted from two elementary steps, the first is conjugate addition of thiolate to an enoate generating an enolate, which is then protonated to complete the addition reaction. Therefore, the protonation in the second step can be expected to proceeds stereoselectively in a manner of 1,2-asymmetric induction, provided that the $\mathrm{C}-\mathrm{S}$ bond could be formed enantioselectively in the first addition step.

The reaction of $\alpha, \beta$-disubstituted enoate 11 with thiol 2e gave $\mathbf{1 3}$ as a sole product in quantitative yield with $95 \%$ ee (Scheme 1). These results indicate that the protonation proceeds anti to $\mathrm{C}-\mathrm{S}$ bond of an enolate conformation $\mathbf{1 2}$ which was formed by enantioselective attack of lithium thiolate under the control of chiral ligand. This observation agreed with the stereospecific addition of thiophenol to $\alpha, \beta$-disubstituted enoate in the absence of the chiral ligand, in which the protonation proceeds anti to $\mathrm{C}-\mathrm{S}$ bond by the stereoelectronic effect of arylthio group..$^{58-60)}$

\section{CATALYTIC ASYMMETRIC PROTONATION REACTION ${ }^{61)}$}

An enolate generated by conjugate addition of thiolate to $\alpha$-substituted acrylate has two stable con-
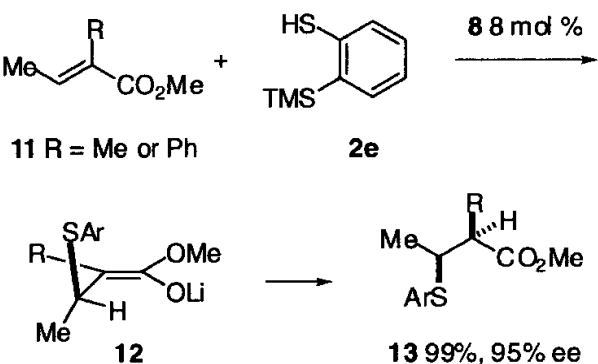

Scheme 1. Catalytic Asymmetric Addition-Protonation

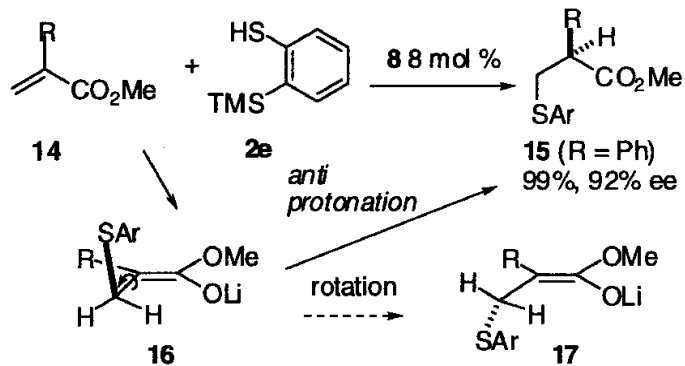

Scheme 2. Conjugate Addition-Asymmetric Protonation

formations, 16 and 17, which are enantiomeric each other (Scheme 2). Catalytic asymmetric protonation to the ester $\alpha$-position would be possible, if the enolate 16, generated by enantioselective conjugate addition of thiolate under the control of chiral ligand, is rapidly protonated before the conformation change to $\mathbf{1 7}$ takes place through rotation of $\sigma$-bond connecting $\alpha$ - and $\beta$-carbons. The present asymmetric protonation reaction is unique in the term of catalytic amount of lithium. Generally in the asymmetric protonation reaction, stoichiometric amounts of metal enolate and chiral source are used, ${ }^{62-64)}$ and the use of the catalytic amount of lithium is a challenging task. $37,40,48,49,65,66)$

The reaction of methyl atropate $\mathbf{1 4}(\mathrm{R}=\mathrm{Ph})$ with 2e in the presence of $8 \mathrm{~mol} \%$ of $\mathbf{8}$ gave protonation product $15(\mathrm{R}=\mathrm{Ph})$ in quantitative yield with $92 \%$ ee. This result indicates that the protonation of enolate $\mathbf{1 6}$ is faster than conformational change to $\mathbf{1 7}$ through rotation of the $\sigma$-bond. The protonation products were desulfurized to the corresponding propionates without any loss of optical purity as has been successfully converted $15 \quad(\mathrm{R}=6$-methoxy-2naphthyl) to $(S)$-naproxene (Scheme 3$)$. 
<smiles>C=C(C(C)=O)c1ccc2cc(OC)ccc2c1</smiles>

14

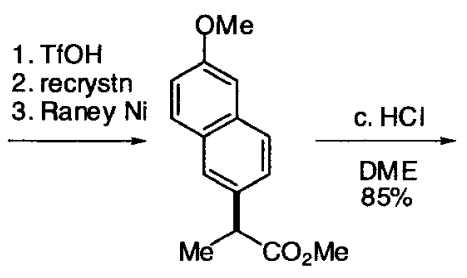

$82 \%, 99 \%$

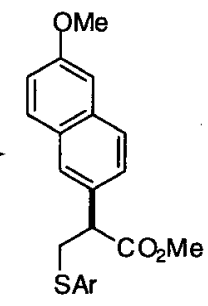

15 99\%, 91\% ee<smiles>COc1ccc2cc(C(C)C(=O)O)ccc2c1</smiles>

(S)-naproxene
Scheme 3. Synthesis of $(S)$-Naproxene

\section{TANDEM MICHAEL-ALDOL CARBON- CARBON BOND-FORMING REACTION ${ }^{67)}$}

We then challenged to the novel stereoselective carbon-carbon bond-forming reaction of the transient enolate intermediate, generated by conjugate addition of the lithium thiolate to an enoate. Though several reports on thiolate-initiated tandem $\mathrm{C}-\mathrm{C}$ bond-forming reaction were known, the stereochemistry of the reactions were not addressed. ${ }^{68-72)}$ Lithium ester enolate having a phenylthio group at the $\beta$-position is unstable and prone to eliminate the lithium thiolate to form an enoate. Conjugate addition reaction of lithium thiolate $\mathbf{1 8}$ to an enoate $\mathbf{1}$ was carried out in the presence of aldehyde $19(\mathrm{R}=\mathrm{Ph})$ as a carbo-electrophile in order to trap a carbonucleophile $\mathbf{2 0} \mathrm{im}$ mediately (Scheme 4). However, tandem Michael-aldol product $21(\mathrm{R}=\mathrm{Ph})$ was obtained only in $52 \%$ yield. The unexpected low yield was ascribed to the reverse reaction of lithium alkoxide 21-Li to the starting compounds through retro-aldol and retroMichael reactions.

Conversion of 21-Li to a silyl ether 21-TMS is one of the solutions for this problem. Thus, the reaction of 1 and $19(\mathrm{R}=\mathrm{Ph})$ was catalyzed by a catalytic amount of thiolate 18 (0.2 equiv) in the presence of phenylthiotrimethylsilane (PhSTMS) to afford, after aqueous workup, $21(\mathrm{R}=\mathrm{Ph})$ in $96 \%$ yield. Perfect stereochemical control was possible in the reaction of 1 with pivalaldehyde $19(\mathrm{R}=t-\mathrm{Bu})$ to afford $21(\mathrm{R}=$ $t$ - $\mathrm{Bu})$ as a sole product among four possible stereoisomers.
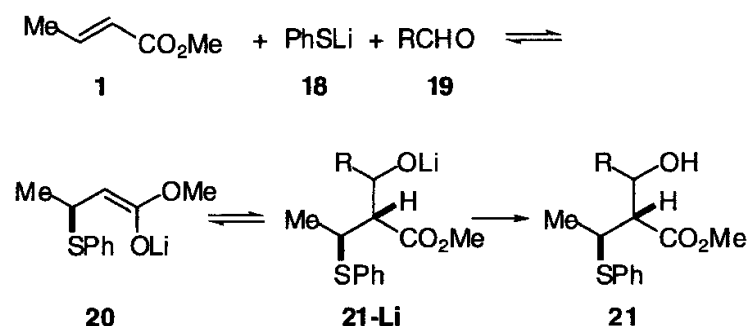

Scheme 4. Michael-Aldol Tandem Reaction

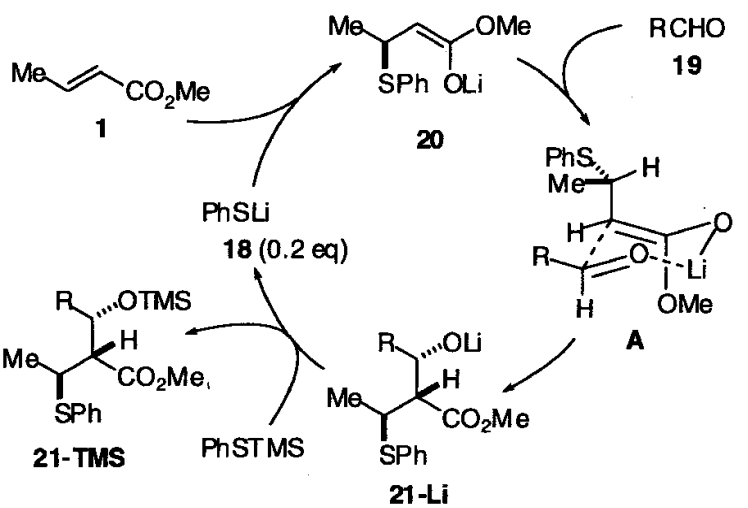

Scheme 5. Lithium Thiolate-Catalyzed Michael-Aldol Reaction

It is also noteworthy that a catalytic amount of lithium thiolate is enough to catalyze the carbon-carbon bond formation because the lithium thiolate $\mathbf{1 8}$ is regenerated through lithium-TMS exchange of 21-Li with PhSTMS (Scheme 5). The stereoselectivity of this tandem reaction is predictable as follows. The conformation of the enolate is fixed by an allylic strain, and the approach of aldehyde takes place anti to $\mathrm{C}-\mathrm{S}$ bond with a coordination of aldehyde oxygen to lithium as shown in A. Coincidently to us, Kamimura's group reported similar stereoselectivity in thiolate-initiated Michael-aldol tandem reaction of acrylates with aldehydes. ${ }^{73-74)}$

\section{MICHAEL-ALDOL TANDEM CYCLIZATION REACTION $^{75}$}

Stereoselective Michael-aldol tandem cyclization reaction was developed by an extension of the intermolecular reaction to an intramolecular reaction of $\omega$-oxo- $\alpha, \beta$-enoate which has enoate and aldehyde moieties in a molecule. Tandem cyclization reactions, especially Michael-Michael reactions, have been reported with the reflection of an importance of ring skeleton construction. ${ }^{76-84)}$ 


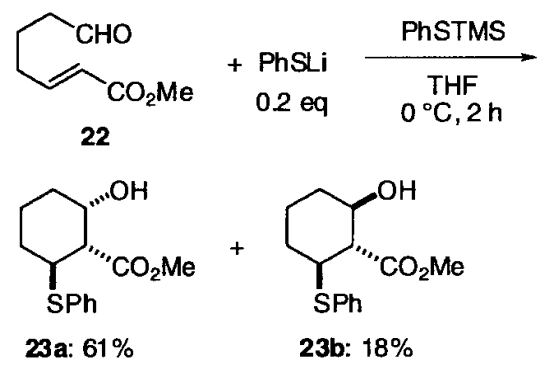

Scheme 6. Lithium Thiolate-Catalyzed Michael-Aldol Tandem Cyclization

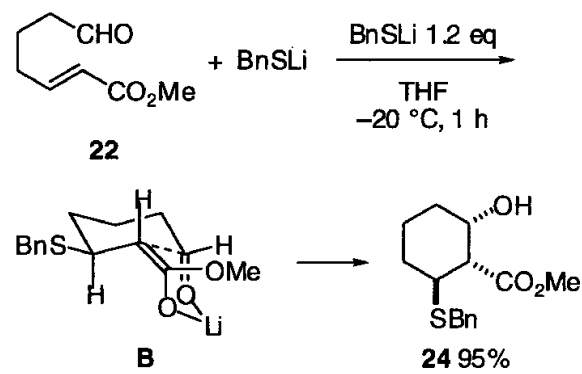

Scheme 7. Lithium Benzylthiolate-Initiated Michael-Aldol Tandem Cyclization

The reaction of $\mathbf{2 2}$ with catalytic amount of lithium thiolate in the presence of PhSTMS proceeded through conjugate addition of thiolate and subsequent aldol reaction of resulting enolate with aldehyde to give cyclization products $\mathbf{2 3}$ stereoselectively (Scheme 6). In this cyclization reaction, PhSTMS was also necessary to afford high chemical yield. Actually, 23a and 23b were obtained only in $24 \%$ and 5 $\%$ yields in the reaction of $\mathbf{2 2}$ with stoichiometric amount of lithium thiolate in the absence of PhSTMS.

As another solution to shift the equilibrium to product side, it was also effective to use lithium benzylthiolate which has higher nucleophilicity and lower pKa (as its thiol) than thiophenolate (Scheme 7). The reaction of $\mathbf{2 2}$ with lithium benzylthiolate gave cyclization product $\mathbf{2 4}$ in quantitative yield with a perfect stereoselectivity. The stereoselectivity of this cyclization reaction was also predictable by the stereochemical model $\mathbf{B}$ where similar controlling factors are operative as shown in $\mathbf{A}$ (Scheme 5 and 7).

\section{TOTAL SYNTHESIS OF (-)-NEPLANOCIN $A^{85)}$}

Neplanocin A (32) is endowed with attractive biological activities including anti-tumor and anti-virus, and has been a synthetic target because of its
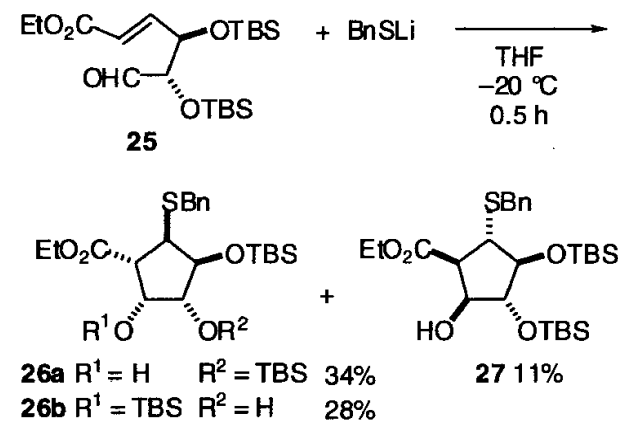

Scheme 8. Stereoselective Cyclization of Chiral $\omega$-Oxo- $\alpha, \beta$ Unsaturated Ester

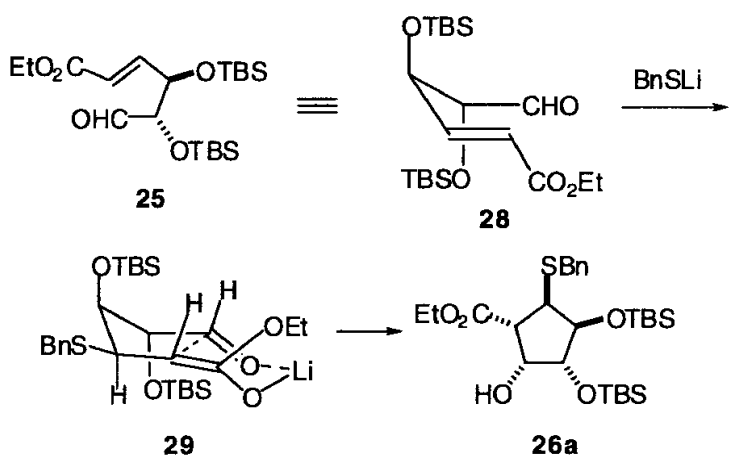

Scheme 9. Stereoselection

challenging structural features. Key to the synthesis of (-)-neplanocin $\mathrm{A}$ is a stereoselective construction of five-membered carbosugar moiety, where all five carbons are functionalized. Michael-aldol tandem cyclization reaction is the ideal for the construction of such five-membered ring. Though several synthetic routs to (-)-neplanocin A are reported, there is no precedent of the ring construction by an aldol reaction.

The reaction of chiral $\omega$-oxo- $\alpha, \beta$-unsaturated ester $\mathbf{2 5}$, which was prepared from D-mannitol, with lithium benzylthiolate gave desired cyclization products 26a, 26b in $62 \%$ and 27 in $11 \%$ yields, respectively (Scheme 8). The diastereofacial selectivity of conjugate addition of the thiolate in the first step was $85: 15$, and the selectivity of aldol cyclization in the second step was perfect. The stereoselective construction of 26, all carbon atoms of which are functionalized, is a big feature of this cyclization reaction.

Two TBSO groups of $\mathbf{2 5}$ fix the conformation of it to anti avoiding the mutual steric repulsion as shown in 28. ${ }^{86-88)}$ Lithium thiolate attacks 28 from the face of the carbon-carbon double bond opposite to aldehyde to form an enolate 29. Conformational control 


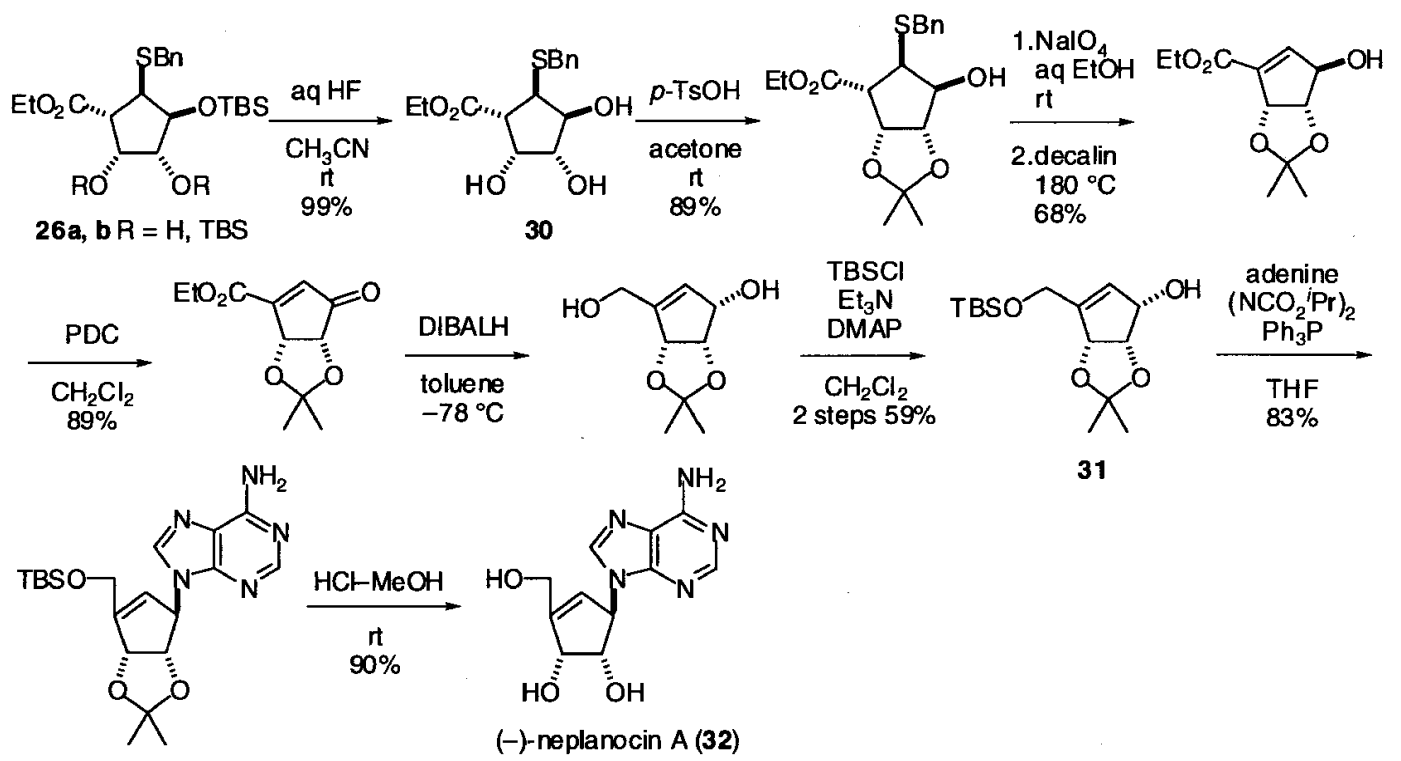

Scheme 10. Synthesis of (-)-Neplanocin A (32)

of the enolate by allylic strain and coordination of the aldehyde oxygen to lithium result in stereoselective cyclization to afford product $\mathbf{2 6}$ predominantly (Scheme 9) .

Cyclization products 26a, 26b were converted to the same alcohol 30 of which benzylsulfanyl group was then thermally eliminated to give an olefin part (Scheme 10). Standard synthetic operation gave 31, the known Ogasawara's ${ }^{89)}$ intermediate of neplanocin A. The structure of $\mathbf{3 1}$ was confirmed by comparison of NMR spectrum provided from Prof. Ogasawara, achieving the formal synthesis. Remaining conversions were followed by reported rout to give (-) neplanocin A.

It is remarkable that the roles of thiolate are multiple, the enolate-generating agent which achieves cyclization, the stereoselectivity-control factor, and the substituent which is convertible to other functional group. The synthetic organic chemistry using thiol did newly expand. It will be also possible to apply this cyclization reaction to the synthesis of cyclitols and carbosugars.

\section{CONCLUSION}

We outlined our challenge to development of asymmetric conjugate addition reaction of thiols catalyzed by an external chiral ligand which enhances the reactivity of thiolate and simultaneously controls a structure of active species, and its extension to carbon-carbon bond-forming reaction. The key to success to highly selective asymmetric conjugate addition reaction is double activation of thiol, which is originally excellent nucleophile, by lithiation and chelate formation with chiral ligand. It is also shown that transient lithium enolate generated by conjugate addition of lithium thiolate is applicable to asymmetric protonation, stereoselective $\mathrm{C}-\mathrm{C}$ bond formation, and intramolecular cyclization reaction. Furthermore, the usefulness of these reactions in synthetic organic chemistry was verified by referring to the synthesis of $(-)$-neplanocin A. Successful total synthesis of (-) -neplanocin A is the evidence as the powerful synthetic tool for the conjugate addition technology of a thiol.

\section{ACKNOWLEDGMENTS}

One of authors (KT) started this work with Ms Shino Manabe when KT was in the University of Tokyo. KT appreciates very much every kind of supports provided by Prof. Kenji Koga. We gratefully acknowledge financial support from Japan Society for Promotion of Science (RFTF-96P00302 "Future Asymmetric Reaction Process"), the Ministry of Education, Culture, Sports, Science and Technology, Japan (Priority Areas (A) "Exploitation of MultiElement Cyclic Molecules"), and Takeda Science Foundation. KN was supported by a fellowship from the JSPS and a research grant from Ajinomoto Co., Ltd. We are grateful to many able coworkers whose names are appeared in the literatures. 


\section{REFERENCES}

1) Tomioka K., Shindo M., Koga K., J. Am. Chem. Soc., 111, 8266-8268 (1989).

2) Shindo M., Koga K., Tomioka K., J. Am. Chem. Soc., 114, 8732-8733 (1992).

3) Asano Y., Iida A., Tomioka K., Tetrahedron Lett., 38, 8973-8976 (1997).

4) Shindo M., Koga K., Tomioka K., J. Org. Chem., 63, 9351-9357 (1998) .

5) Taniyama D., Hasegawa M., Tomioka K., Tetrahedron Lett., 41, 5533-5536 (2000).

6) Hasegawa M., Taniyama D., Tomioka K., Tetrahedron, 56, 10153-10158 (2000) .

7) Tomioka K., Shioya Y., Nagaoka Y., Yamada K., J. Org. Chem., 66, 7051-7054 (2001).

8) Asano Y., Yamashita M., Nagai K., Kuriyama M., Yamada K., Tomioka K., Tetrahedron Lett., 42, 8493-8495 (2001).

9) Kanai M., Tomioka, K., Tetrahedron Lett., 36, 4273-4274, 4275-4278 (1995).

10) Nakagawa Y., Kanai M., Nagaoka Y., Tomioka K., Tetrahedron, 54, 10295-10307 (1998) .

11) Kanai M., Nakagawa Y., Tomioka K., Tetrahedron, 55, 3843-3854 (1999).

12) Mori T., Kosaka K., Nakagawa Y., Nagaoka Y., Tomioka K., Tetrahedron: Asymmetry, 9, 3175-3178 (1998).

13) Fujihara H., Nagai K., Tomioka K., J. Am. Chem. Soc., 122, 12055-12056 (2000).

14) Nagai K., Fujihara H., Kuriyama M., Yamada K., Tomioka K., Chem. Lett., 8-9 (2002) .

15) Mizuno, M., Fujii K., Tomioka K., Angew. Chem., Int. Ed. Engl., 37, 515-517 (1998).

16) Nagaoka Y., Tomioka K., Org. Lett., 1, 14671469 (1999).

17) Nagaoka Y., Tomioka K., J. Org. Chem., 63, 6428-6429 (1998).

18) Nagaoka Y., Inoue H., Nawal E-K., Tomioka K., Chem. Commun., 122-123 (2002).

19) Inoue H., Nagaoka Y., Tomioka K., J. Org. Chem., 67, 5864-5867 (2002).

20) Fujieda H., Kanai M., Kambara T., Iida A., Tomioka K., J. Am. Chem. Soc., 119, 20602061 (1997).

21) Hussein M. A., Iida A., Tomioka K., Tetrahedron, 55, 11219-11228 (1999) .

22) Kambara T., Tomioka K., J. Org. Chem., 64, 9282-9285 (1999).
23) Tomioka K., Synthesis, 541-549, (1990).

24) Tomioka K., Nagaoka Y., "Comprehensive Asymmetric Catalysis," eds. by Jacobsen E. N., Pfaltz A., Yamamoto H., Springer, 1999, Vol. III, chapter 31 .

25) Tomioka K. "Modern Carbonyl Chemistry," ed. by Otera J., Wiley-VCH, Weinheim, 2000, chapter 12 .

26) Tomioka K., Hasegawa M., J. Synth. Org. Chem. Jpn., 58, 848-855 (2000).

27) Iguchi M., Yamada K., Tomioka K., "Topics in Organometallic Chemistry," ed. by Hodgson D. M., Springer, Heidelberg, (in press) .

28) Tanaka Y., Nishimura K., Tomioka K., Heterocycles, 58, 71-73 (2002).

29) Recent review on metal-catalyzed $\mathrm{C}-\mathrm{S}$ bond formation: Kondo, T., Mitsudo T., Chem. Rev., 100, 3205-3220 (2000).

30) For impressive enantioselective alkylation at the $\alpha$-position of sulfur, see: Nakamura S., Nakagawa R., Watanabe Y., Toru T., J. Am. Chem. Soc., 122, 11340-11347 (2000).

31) Nakamura S., Nakagawa R., Watanabe Y., Toru T., Angew. Chem., Int. Ed. Engl., 39, 353-355 (2000).

32) Wynberg H., Greijdanus B., Tetrahedron Lett., 38, 427-428 (1977).

33) Hiemstra H., Wynberg H., J. Am. Chem. Soc., 103, 417-430 (1981).

34) Suzuki K., Ikegawa A., Mukaiyama T., Bull. Chem. Soc. Jpn., 55, 3277-3282 (1982).

35) Yamashita H., Mukaiyama T., Chem. Lett., 363-366 (1985).

36) Review: Mikolajczyk M., Drabowicz J., Kielbasinski P., "Methods of Organic Chemistry, Vol. E21e, Stereoselective Synthesis," Georg Thime Verlag, Stuttgart, 1995, chapter 5.

37) Kobayashi N., Iwai K., J. Am. Chem. Soc., 100, 7071-7072 (1978).

38) Kobayashi N., Polymer J., 13, 263-271 (1981).

39) Keniya J., Natu A. A., Gogte V. N., Chem. Ind., 243 (1986).

40) Kumar A., Salunkhe R. V., Rane R. A., Dike S. Y., J. Chem. Soc., Chem. Commun., 485486 (1991).

41) Toda F., Tanaka K., Sato J., Tetrahedron: Asymmetry, 4, 1771-1774 (1993).

42) Tomioka K., Okuda M., Nishimura K., 
Manabe S., Kanai M., Nagaoka Y., Koga K., Tetrahedron Lett., 39, 2141-2144 (1998) .

43) Tomioka K., Kawasaki H., Yasuda K., Koga K., J. Am Chem. Soc., 110, 3597-3601 (1988).

44) Nishimura K., Ono M., Nagaoka Y., Tomioka K., J. Am. Chem. Soc., 119, 12974-12975 (1997).

45） S-Garwood D., J. Org. Chem., 37, 3797-3803 (1972).

46) Banister A. J., Clegg W., Gill W. R., J. Chem. Soc., Chem. Commun., 850-852 (1987).

47) For hemilabile ligand, see: Kuriyama M., Nagai K., Yamada K., Miwa Y., Taga T., Tomioka K., J. Am. Chem. Soc., 124, 89328939 (2002).

48) Emori E., Arai T., Sasai H., Shibasaki M., J. Am. Chem. Soc., 120, 4043-4044 (1998).

49) Emori E., Iida T., Shibasaki M., J. Org. Chem., 64, 5318-5320 (1999).

50) Nishide K., Shigeta Y., Obata K., Node M., J. Am. Chem. Soc., 118, 13103-13104 (1996).

51) Node M., Nishide K., Shigeta Y., Shiraki H., Obata K., J. Am. Chem. Soc., 122, 1927-1936 (2000).

52) Kanemasa S., Oderaotoshi Y., Wada E., $J$. Am. Chem. Soc., 121, 8675-8676, (1999).

53) Saito M., Nakajima M., Hashimoto S., Chem. Commun., 1851-1852 (2000) .

54) Saito M., Nakajima M., Hashimoto S., Tetrahedron, 56, 9589-9594 (2000).

55) Nishimura K., Tomioka K., J. Org. Chem., 67, 431-434 (2002).

56) Chamberlin A. R., Reich S. H., J. Am. Chem. Soc., 107, 1440-1441 (1985).

57) "Stereochemistry of Organic Compounds," eds. by Eliel E. L., Wilen S.H., Mander L. N., Wiley-Interscience, New York, 1994, Chapter 10-5, pp. 647-655.

58) Miyata O., Shinada T., Ninomiya I., Naito T., Date T., Okamura K., Inagaki S., J. Org. Chem., 56, 6556-6564 (1991).

59) For thiol addition to nitroolefin, see: Kamimura A., Sasatani H., Hashimoto T., Kawai T., Hori K., Ono N., J. Org. Chem., 55, 2437-2442 (1990).

60) Hori K., Higuchi S., Kaminura A., J. Org. Chem., 55, 5900-5905 (1990).

61) Nishimura K., Ono M., Nagaoka Y., Tomioka
K., Angew. Chem., Int. Ed. Engl., 40, 440442 (2001).

62) Review: Helmchen G., Hoffmann R. W., Mulzer J., Schaumann E. "Methods of Organic Chemistry, Vol. E21d, Stereoselective Synthesis," Georg Thime Verlag, Stuttgart, 1995, chapter 2.

63) Fehr C., Angew. Chem., Int. Ed. Engl., 35, 2567-2587 (1996).

64) Yanagisawa A., Ishihara K., Yamamoto H., Synlett, 411-420 (1997).

65) Pracejus H., Wilcke F.-W., Hanemann K., $J$. Prakt. Chem., 319, 219-229 (1977).

66) Fehr C., Stempf I., Galindo J., Angew. Chem., Int. Ed. Engl., 32, 1044-1046 (1993) .

67) Ono M., Nishimura K., Nagaoka Y., Tomioka K., Tetrahedron Lett., 40, 1509-1512 (1999) .

68) Shono T., Matsumura Y., Kashimura S., Hatanaka K., J. Am. Chem. Soc., 101, 47524753 (1979).

69) Watanabe M., Shirai K., Kumamoto T., Bull. Chem. Soc. Jpn., 52, 3318-3320 (1979).

70) Itoh A., Ozawa S., Oshima K., Nozaki H., Bull. Chem. Soc. Jpn., 54, 274-278 (1981).

72) Yura T., Iwasawa N. Mukaiyama T., Chem. Lett., 187-190 (1986).

73) Kamimura A., Mitsudera H., Asano S., Kakehi A., Noguchi M. Chem. Commun., 10951096 (1998).

74) Kamimura A., Mitsudera H., Asano S., Kidera S., Kakehi A., J. Org. Chem., 64, 6353-6360 (1999).

75) Ono M., Nishimura K., Nagaoka Y., Tomioka K., Tetrahedron Lett., 40, 6979-6982 (1999) .

76) For Michael-Michael cyclization, see: Uyehara T., Shida N., Yamamoto Y., J. Org. Chem., 57, 3139-3146 (1991).

77) Saito S., J. Syn. Org. Chem. Jpn., 50, 316-325 (1992).

78) Ihara M., Makita K., Tokunaga Y., Fukumoto K., J. Org. Chem., 59, 6008-6013 (1994).

79) Yoshii E., Hori K., Nomura K., Yamaguchi K., Synlett, 568-570 (1995).

80) Yoshizaki H., Tanaka T., Yoshii E., Koizumi T., Takeda K., Tetrahedron Lett., 39, 47-50 (1998).

81) For Michael-aldol cyclization, see: Itoh A., Ozawa S., Ohshima K., Nozaki H., Bull. Chem. Soc. Jpn., 54, 274-278 (1981). 
82) Armstead D. M., Danishefsky S. L., Tetrahedron Lett., 28, 4959-4962 (1987).

83) Ihara M., Taniguchi T., Makita K., Takano M., Ohnishi M., Taniguchi M., Fukumoto K., Kabuto C., J. Am. Soc. Chem., 115, 81078115 (1993).

84) Magnus P., Miknis G. F., Press N. J., Grandjean D., Taylor G. M., Harling J., J. Am. Chem. Soc., 119, 6739-6748 (1997).

85) Ono M., Nishimura K., Tsubouchi H., Nagaoka Y., Tomioka K., J. Org. Chem., 66, 8199-
8203 (2001).

86) Saito S., Narahara O., Ishikawa T., Asahara M., Moriwake T., Gawronski J., Kazmierczak F., J. Org. Chem., 58, 6292-6302 (1993).

87) Gung B. W., Zhu Z., Fouch R. A., J. Am. Chem. Soc., 117, 1783-1788 (1995).

88) Saito S., Ishikawa A., J. Synth. Org. Chem. Jpn., 56, 86-95 (1998).

89) Yoshida N., Kamikubo T., Ogasawara K., Tetrahedron Lett., 39, 4677-4678 (1998). 